\title{
Physiotherapy intervention in Parkinson's disease: systematic review and meta-analysis
}

\author{
(c) $(1 \otimes$ OPEN ACCESS
}

Claire L Tomlinson systematic reviewer ${ }^{1}$, Smitaa Patel statistician ${ }^{1}$, Charmaine Meek research assistant ${ }^{1}$, Clare P Herd research associate ${ }^{2}$, Carl E Clarke professor ${ }^{23}$, Rebecca Stowe senior systematic reviewer ${ }^{1}$, Laila Shah research administrator ${ }^{1}$, Catherine Sackley professor of physiotherapy research ${ }^{4}$, Katherine H O Deane senior lecturer in research ${ }^{4}$, Keith Wheatley professor $^{5}$, Natalie Ives senior statistician ${ }^{1}$

${ }^{1}$ Birmingham Clinical Trials Unit, University of Birmingham, Birmingham B15 2TT, UK; ${ }^{2}$ School of Clinical and Experimental Medicine, College of Medicine and Dental Sciences, University of Birmingham; ${ }^{3}$ Department of Neurology, Sandwell and West Birmingham Hospitals NHS Trust, City Hospital, Birmingham; ${ }^{4}$ University of East Anglia, Norwich, UK; ${ }^{5}$ Cancer Research UK Clinical Trials Unit, School of Cancer Sciences, University of Birmingham

\begin{abstract}
Objective To assess the effectiveness of physiotherapy compared with no intervention in patients with Parkinson's disease.

Design Systematic review and meta-analysis of randomised controlled trials.

Data sources Literature databases, trial registries, journals, abstract books, and conference proceedings, and reference lists, searched up to the end of January 2012.

Review methods Randomised controlled trials comparing physiotherapy with no intervention in patients with Parkinson's disease were eligible. Two authors independently abstracted data from each trial. Standard meta-analysis methods were used to assess the effectiveness of physiotherapy compared with no intervention. Tests for heterogeneity were used to assess for differences in treatment effect across different physiotherapy interventions used. Outcome measures were gait, functional mobility and balance, falls, clinician rated impairment and disability measures, patient rated quality of life, adverse events, compliance, and economic analysis outcomes.
\end{abstract}

Results 39 trials of 1827 participants met the inclusion criteria, of which 29 trials provided data for the meta-analyses. Significant benefit from physiotherapy was reported for nine of 18 outcomes assessed. Outcomes which may be clinically significant were speed $(0.04 \mathrm{~m} / \mathrm{s}, 95 \%$ confidence interval 0.02 to $0.06, P<0.001$ ), Berg balance scale (3.71 points, 2.30 to $5.11, P<0.001)$, and scores on the unified Parkinson's disease rating scale (total score -6.15 points, -8.57 to $-3.73, P<0.001$; activities of daily living subscore $-1.36,-2.41$ to $-0.30, P=0.01$; motor subscore $-5.01,-6.30$ to $-3.72, P<0.001)$. Indirect comparisons of the different physiotherapy interventions found no evidence that the treatment effect differed across the interventions for any outcomes assessed, apart from motor subscores on the unified Parkinson's disease rating scale (in which one trial was found to be the cause of the heterogeneity).

Conclusions Physiotherapy has short term benefits in Parkinson's disease. A wide range of physiotherapy techniques are currently used to treat Parkinson's disease, with little difference in treatment effects. Large, well designed, randomised controlled trials with improved methodology and reporting are needed to assess the efficacy and cost effectiveness of physiotherapy for treating Parkinson's disease in the longer term.

\section{Introduction}

Parkinson's disease is a complex neurodegenerative disorder ${ }^{1}$ with wide reaching implications for patients and their families. The management of Parkinson's disease has traditionally centred on drug treatment, ${ }^{2}$ but even with optimal medical management, patients still experience a deterioration of body function, daily

Correspondence to: C Tomlinson c.I.smith.1@bham.ac.uk

Extra material supplied by the author (see http://www.bmj.com/content/345/bmj.e5004?tab=related\#webextra)

Web table 1: Characteristics of included studies

Web table 2: Risk of bias in included studies

Web figure 1: Two or six min walk test $(\mathrm{m})$

Web figure 2: Freezing of gait questionnaire

Web figure 3: 10 or $20 \mathrm{~m}$ walk test (s)

Web figure 4: Unified Parkinson's disease rating scale - activities of daily living

Web figure 5: Unified Parkinson's disease rating scale - total score 
activities, participation, ${ }^{3}$ and decline in mobility. ${ }^{4}$ This can lead to increased dependence on others, inactivity, ${ }^{5}$ and social isolation, ${ }^{4}$ resulting in reduced quality of life. ${ }^{4}$ There has been increasing support for the inclusion of rehabilitation therapies as an adjuvant to pharmacological and neurosurgical treatment, ${ }^{63}$ and a call for the move towards multidisciplinary management. ${ }^{178}$ The physiotherapist is a member within this multidisciplinary team, ${ }^{19}$ with the purpose of maximising functional ability and minimising secondary complications through movement rehabilitation within a context of education and support for the whole person. ${ }^{10}{ }^{11}$ Physiotherapy for Parkinson's disease focuses on transfers, posture, upper limb function, balance (and falls), gait, and physical capacity and (in)activity. It also uses cueing strategies, cognitive movement strategies, and exercise to maintain or increase independence, safety, and quality of life. ${ }^{412}$

Referral rates to physiotherapy for people with Parkinson's disease have historically been low, owing to a weak evidence base and poor availability of physiotherapy services. ${ }^{13}{ }^{14}$ In recent years, supportive evidence for the inclusion of physiotherapy in the management of Parkinson's disease has grown, due to the increased number of trials particularly in the past five years. ${ }^{15}$ Recent management guidelines have supported physiotherapy, such as those from the United Kingdom National Institute for Health and Clinical Excellence (NICE) ${ }^{16}$ and the Royal Dutch Society of Physical Therapy. ${ }^{17}$ This has led to an increased number of referrals, with a survey by Parkinson's UK in 2008 reporting that $54 \%$ of the 13000 members surveyed had seen a physiotherapist. ${ }^{18}$

To synthesise the latest trial reports with the older data, we have performed this systematic review and meta-analysis of all randomised controlled trials of physiotherapy in Parkinson's disease. This review includes trials assessing a variety of different physiotherapy methods as used to treat people with Parkinson's disease, to provide an overall assessment on the use of physiotherapy in this patient population. Previous reviews have focused on one type of physiotherapy (such as exercise or treadmill training). ${ }^{19}{ }^{20}$ Detailed results have been published in the Cochrane Library ${ }^{21}$ updating the Cochrane review published in $2001 .^{11}$

\section{Methods}

\section{Search strategy and selection criteria}

A systematic search of the literature to the end of January 2012 was undertaken using a highly sensitive search strategy as recommended by the Cochrane Collaboration. ${ }^{22}$ We combined text and, where appropriate, Medical Subject Heading terms for physiotherapy, physical therapy, exercise, or rehabilitation; and Parkinson, Parkinson's disease, or parkinsonism. No language restrictions were applied. We identified relevant trials by electronic searches of general biomedical and science electronic databases (Medline, Embase, Cumulative Index to Nursing and Allied Health Literature, Web of Science), rehabilitation databases (Allied and Complimentary Medicine Database, REHABDATA, REHADAT, GEROLIT); English language databases of foreign language research and third world publications (Latin American and Caribbean Health Sciences Literature, MedCarib, Index medicus for the Eastern Mediterranean region); conference and grey literature databases (Conference Proceedings Citation Index, Dissertation Abstracts, Conference Papers Index, Index to Theses, Electronic Theses Online Service, ProQuest), and trial registries (Cochrane Central Register of Controlled Trials, CentreWatch Clinical Trials listing service, metaRegister of Controlled Trials, ClinicalTrials.gov,
Research Portfolio Online Reporting Tools, Physiotherapy Evidence Database, National Institute of disability and rehabilitation register, National research register). We also hand searched relevant general (for example, Lancet, BMJ, JAMA) and specific journals (for example, Movement Disorders, Neurology, Archives of Physical Medicine and Rehabilitation, Clinical Rehabilitation, Physiotherapy, Physical Therapy), abstract books, and conference proceedings (International Congress of Parkinson's Disease and Movement Disorders, World Congress on Parkinson's Disease and Related Disorders), as well as examined the reference lists of identified papers and other reviews.

\section{Study selection}

Studies eligible for this review were randomised controlled trials (including the first phase of crossover trials) of patients with Parkinson's disease comparing a physiotherapy intervention with no intervention or placebo control. Physiotherapy encompasses a wide range of techniques, so we were inclusive in our definition of physiotherapy intervention, including trials of general physiotherapy, exercise, treadmill training, cueing, dance, and martial arts versus no intervention.

General physiotherapy was a broad category, including a variety of techniques traditionally used by physiotherapists to treat people with Parkinson's disease. Trials in this category may include multifaceted interventions using both active participation in treatment by the patient (such as exercise and practising of functional activities) and hands-on techniques delivered by the therapist (for example, massage, passive stretching, the Bobath technique). Exercise interventions were those that included only active exercise participation techniques targeting a variety of symptoms, such as balance, falls prevention, and walking speed. An existing Cochrane review analysed trials of treadmill training for Parkinson's disease, and thus these trials were considered separately to other exercise interventions. Martial arts and dance interventions included participation in universally recognised activities not specifically designed for treating disease, but which appeared in trials of Parkinson's disease evaluating relevant physiotherapy outcome measures. We excluded trials of multidisciplinary team interventions because it was difficult to ascertain the amount of physiotherapy input. Ultimately, all trials were meta-analysed to give an overall picture of the effect of delivery of a physiotherapy intervention versus no physiotherapy intervention.

\section{Data extraction and quality assessment}

All articles were read by two independent review authors (CLT, $\mathrm{SP}, \mathrm{CM}$, or $\mathrm{CPH}$ ) and data extracted according to predefined criteria, with any discrepancies resolved by discussion. Publications were assessed for methodological quality by recording specified eligibility criteria, method of randomisation and blinding, concealment of allocation, similarity of patients in treatment groups at baseline, variation in cointerventions received by patients throughout the trial period, whether an intention to treat analysis was performed, and the number of patients lost to follow-up.

\section{Quantitative data synthesis}

Outcome data included gait outcomes (such as the two or six min walk test, 10 or $20 \mathrm{~m}$ walk test, speed, cadence, stride and step length, freezing of gait questionnaire), functional mobility and balance outcomes (such as the timed up and go test, functional reach test, Berg balance scale, activities specific balance confidence scale), falls data (such as number of falls, 
falls efficacy scale), clinician rated disability scales (such as the unified Parkinson's disease rating scale (UPDRS)), patient rated quality of life (such as Parkinson's disease questionnaire 39), adverse events, compliance or withdrawals, and health economics where available.

Results of each trial were combined using standard meta-analytic methods to estimate an overall effect for physiotherapy versus no intervention. Since all outcomes were continuous variables, weighted mean difference methods were used. ${ }^{23}$ Briefly, for each trial, this involved calculating the mean change (and standard deviation) from baseline to the time point after intervention, for both the intervention and no intervention groups. From these numbers, the mean difference and its variance between arms for each trial could be calculated and then combined using a fixed effects model.

The primary analysis was a comparison of physiotherapy with no intervention (control) using change from baseline to the first assessment after treatment (which, in most cases, was immediately after intervention). This comparison was chosen as the primary analysis, because in most trials it was the main data analysis reported, and few trials reported data at assessment points in the longer term (that is, after six months). Some trials also allowed patients in the control group to receive physiotherapy intervention after this point, so this primary analysis allowed a clean comparison of physiotherapy intervention versus no intervention.

Since the different trials implemented various types of physiotherapy, trials were divided according to the type of intervention (general physiotherapy, exercise, treadmill, cueing, dance, or martial arts). If any trials with three or more treatment arms were identified, we made two assumptions for the analysis. Firstly, if the trial was comparing two or more physiotherapy methods in the same category of intervention (as described above) versus control, then the data for those physiotherapy arms were combined to give one comparison of physiotherapy intervention versus control for that trial.

Secondly, if the trial was comparing two or more physiotherapy methods that were in different categories (as described above) versus control, then the data for those physiotherapy arms were kept separate, and the data for that trial were included in the appropriate physiotherapy categories. Therefore, in some cases, the control arms for some trials were included twice in the analysis. However, this related to only a small number of trials and patients, and it was judged that this double inclusion would not overly influence the analysis. We used tests of heterogeneity to make indirect comparisons to investigate whether the treatment effect differed across the different intervention categories. $^{24}$

\section{Results}

Of 76 potentially relevant studies identified, 31 were excluded (for example, studies were not properly randomised, or crossover trials did not report data for the first intervention period) and six were ongoing trials for which no data were available (fig $1 \Downarrow$ ). Therefore, we included 39 randomised controlled trials of 1827 patients in the systematic review (fig 1 , web table 1). ${ }^{25-63}$ There were nine trials with multiple arms. ${ }^{27} 3137384045525560$ In five trials, two intervention arms were in the same physiotherapy category; therefore, these arms were combined to give one physiotherapy comparison versus no intervention. ${ }^{37} 40525560$ In five trials, two intervention arms were in different physiotherapy categories, so the trial contributed data to two physiotherapy comparisons. ${ }^{27} 31384560$ This meant that these five trials were included multiple times in the analysis, and the control arms from these trials were counted more than once. Therefore, 39 trials contributed data for 44 comparisons within the six different physiotherapy interventions (physiotherapy $n=7$, exercise $n=14$, treadmill training $n=8$, cueing $n=9$, dance $n=2$, and martial arts $\mathrm{n}=4$, table $1 \Downarrow$ ).

\section{Methodological quality}

The amount of methodological detail reported in the trials was variable, with several quality indicators not fully discussed in many publications (fig $2 \Downarrow$, web table 2 ). Only six (15\%) studies $^{26} 3233365759$ reported a sample size calculation in the trial report. Less than half of the trials described the randomisation method used, and information on concealment of treatment allocation was also poorly reported (14 (36\%)). Blinded assessors were used in 24 (62\%) studies (although in one study, the assessors correctly guessed the treatment allocation in nearly $30 \%$ of patients ${ }^{33}$ ). Finally, only nine trials stated intention to treat as the primary method of analysis, 293233363940475763 three trials stated per protocol as the primary method of analysis, ${ }^{345255}$ and the remaining trials did not describe the method of analysis.

\section{Data available for analysis}

Of 13 trials reported in abstract form, five had data available for meta-analysis. ${ }^{34} 37395155$ From the studies with full publications, one trial had relevant data that could not be extracted because it was only available in graph form, ${ }^{56}$ and another trial published only median and interquartile range data, which could not be meta-analysed in this format..$^{30}$ Therefore, data were not available from ten trials, and data available for meta-analysis was provided by 29 trials.

\section{Effects of intervention \\ Gait outcomes}

Speed was significantly increased with physiotherapy compared with no intervention (mean difference $0.04 \mathrm{~m} / \mathrm{s}, 95 \%$ confidence interval 0.02 to $0.06 ; \mathrm{P}<0.001$, fig $3 \Downarrow$ ). There were also benefits of borderline significance for the two or six minute walk test and the freezing of gait questionnaire. We saw a greater increase in the distance walked in two or six mins $(13.37 \mathrm{~m}, 0.55$ to 26.20; $\mathrm{P}=0.04$, web figure 1) and an improvement in score for the freezing of gait questionnaire $(-1.41,-2.63$ to -0.19 ; $\mathrm{P}=0.02$, web figure 2 ) after physiotherapy. By contrast, we saw borderline significance in favour of no intervention for the time taken to walk 10 or $20 \mathrm{~m}(0.40 \mathrm{~s}, 0.00$ to $0.80 ; \mathrm{P}=0.05$, web figure 3$)$. There was no significant difference between physiotherapy and no intervention for cadence $(-1.57 \mathrm{steps} / \mathrm{min}$, -3.81 to $0.67 ; \mathrm{P}=0.17)$, stride length $(0.03 \mathrm{~m},-0.02$ to 0.08 ; $\mathrm{P}=0.24)$, and step length $(0.02 \mathrm{~m}, 0.00$ to $0.04 ; \mathrm{P}=0.06)$, (table $2 \Downarrow)$.

\section{Functional mobility and balance outcomes}

We found significant improvements with physiotherapy for the timed up and go test $(-0.63 \mathrm{~s}, 95 \%$ confidence interval -1.05 to $-0.21 ; \mathrm{P}=0.003)$, functional reach test $(2.16 \mathrm{~cm}, 0.89$ to 3.43 ; $\mathrm{P}<0.001$ ), and Berg balance scale (3.71 points, 2.30 to 5.11;

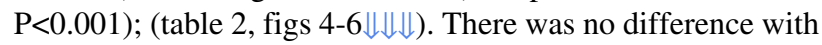
physiotherapy compared with no intervention for activity specific balance confidence scale ( 2.40 points, -2.78 to 7.57 ; $\mathrm{P}=0.36$; table 2).

In the analysis for the timed up and go test, one trial was heavily weighted in the analysis owing to small standard deviations compared with other studies (fig 4) ${ }^{60}$ Furthermore, in the trial publication, a non-significant effect of martial arts intervention 
was reported ( $\mathrm{P}=0.093)$, but when the data as reported in the paper were included in our analysis, a significant difference was found $(\mathrm{P}=0.003)$. We contacted the authors of this study to check whether the data reported in the paper were in fact standard errors, but they were confirmed as standard deviations. We therefore performed a sensitivity analysis, removing this study, and found that the overall result became not significant $(-0.38$ s, $95 \%$ confidence interval -0.96 to $0.21 ; \mathrm{P}=0.21$ ); thus, this result should be interpreted with caution.

\section{Falls}

Seven trials collected data for falls using a falls diary, reporting either the number of patients falling or the number of falls per patient. ${ }^{33} 363950576162$ For both outcomes, there was a decrease in falls after physiotherapy. However, only three studies compared the two treatment groups, with two reporting no difference between the arms, ${ }^{50}{ }^{57}$ and one reporting a significant difference favouring physiotherapy intervention. ${ }^{61} \mathrm{We}$ saw no difference in the falls efficacy scale between the two treatment arms ( -1.91 points, $95 \%$ confidence interval -4.76 to 0.94 ; $\mathrm{P}=0.19$; table 2).

\section{Clinician rated disability on UPDRS}

The UPDRS motor score improved with physiotherapy compared with no intervention ( -5.01 points, $95 \%$ confidence interval -6.30 to $-3.72 ; \mathrm{P}<0.001$, fig $7 \Downarrow$ ). We also saw significant improvements in the UPDRS subscore for activities of daily living ( -1.36 points, -2.41 to $-0.30 ; \mathrm{P}=0.01$; web figure $4)$ and total scores with physiotherapy $(-6.15,-8.57$ to -3.73 ; $\mathrm{P}<0.001$; web figure 5), but no difference in mental subscore $(-0.44,-0.98$ to $0.09 ; \mathrm{P}=0.10$; table 2$)$.

\section{Patient rated quality of life using Parkinson's disease questionnaire 39}

Only data for the mobility domain and summary index of the Parkinson's disease questionnaire 39 were available for meta-analysis. We saw no difference between treatment arms for either overall patient rated quality of life using the summary index ( -0.38 points, $95 \%$ confidence interval -2.58 to 1.81 ; $\mathrm{P}=0.73)$ or the mobility domain $(-1.43,-8.03$ to $5.18 ; \mathrm{P}=0.67)$.

\section{Treatment compliance, adverse events, and health economics}

Only 14 trials discussed patient compliance, with $12^{262932} 363739-4147495963$ quantifying it in some form. No trials reported data for health economics, and only one commented on adverse events, stating that none had occurred during treatment sessions. ${ }^{36}$

\section{Subgroup analysis}

Only one outcome, the UPDRS motor subscore, showed significant heterogeneity between the treatment effects of the different classes of intervention. In all other cases, there was no evidence of any differences (table 2). One outlying trial was the cause of this heterogeneity in the motor score $;^{34}$ when this trial was excluded from the analysis, the result remained significant ( -3.77 points, $95 \%$ confidence interval -5.15 to -2.39 ;

$\mathrm{P}<0.001)$, but the test for between trial and between subgroup heterogeneity was no longer significant $(\mathrm{P}=0.44$ and $\mathrm{P}=0.08$, respectively).

\section{Discussion}

A variety of physiotherapy methods are used to treat people with Parkinson's disease. Previous reviews have focused on one type of physiotherapy (for example, exercise, treadmill training). ${ }^{19}{ }^{20}$ This review brings together all the evidence from the numerous trials evaluating the various physiotherapy methods into one review to assess the overall effect of physiotherapy versus no physiotherapy, and it also allows an indirect comparison of the different physiotherapy methods used.

This review provides evidence on the efficacy of physiotherapy in the short term (mean follow-up <three months), in the treatment of Parkinson's disease. Significant benefit of physiotherapy was reported for nine outcomes: gait speed, two or six min walk test, freezing of gait questionnaire, timed up and go test, functional reach test, Berg balance scale, and UPDRS (total scores, activities of daily living and motor subscores). Although most of the observed differences between the two treatment groups were small, the improvements seen for speed, Berg balance scale, and UPDRS scores were at levels that may be of clinical importance. ${ }^{64-67}$ By contrast, the only patient rated quality of life outcome measure (Parkinson's disease questionnaire 39) showed no significant benefit from treatment with physiotherapy, and was only reported in eight trials.

The review also highlights the wide range of physiotherapy techniques being used in the treatment of Parkinson's disease. Indirect comparisons provided no evidence of differences in the treatment effect between different types of physiotherapy. With all this in mind and considering the low methodological quality, small size, and short duration of many of the included trials, this evidence supporting the use of physiotherapy for people with Parkinson's disease must be balanced against the lack of long term evidence currently available.

\section{Clinical implications}

We saw no evidence of an improvement in patient rated quality of life after physiotherapy, and the observed differences in the nine significant outcomes were relatively small. Their relevance and benefit to patients with Parkinson's disease must be put into context, in terms of what is considered a recommended minimally important difference. Little good quality evidence is available for minimal clinically important differences in these outcome measures. Data for the minimally important difference of walking speed is lacking for people with Parkinson's disease, but a small cohort study of patients with stroke has been reported. Perry and colleagues ${ }^{64}$ reported that an increase in speed of just $0.03 \mathrm{~m} / \mathrm{s}$ could translate into a change from a limited to an unlimited household walker. The improvement in speed of $0.04 \mathrm{~m} / \mathrm{s}$ with physiotherapy reported here accords with the findings of the Perry study. ${ }^{64}$

Data for minimally important differences for the two or six min walk test and the freezing of gait questionnaire are also lacking. Therefore, while a $13 \mathrm{~m}$ increase in distance walked would probably be considered clinically important, the importance of a 1.4 point improvement in the freezing of gait questionnaire is less clear. Five points has been reported by a small test-retest study as the minimal detectable change on the Berg balance scale. ${ }^{65}$ In this review, we recorded a four point improvement after physiotherapy for this outcome. The minimally important difference for the timed up and go test in Parkinson's disease patients is $11 \mathrm{~s},{ }^{65}$ which is much larger than the $0.6 \mathrm{~s}$ improvement observed within this review. Similarly, the $2 \mathrm{~cm}$ improvement in the functional reach test seen in this review 
was lower than the minimally important difference of $9 \mathrm{~cm}$ and

$7 \mathrm{~cm}$ for forward and backward functional reach tests, respectively. ${ }^{65}$ The small changes observed in this review may, for some outcomes, translate into clinically relevant improvements in a person's functional mobility. A greater evidence base is required to support or refute the clinical significance of these results.

We also observed significant improvements after physiotherapy intervention for clinician rated UPDRS scores (that is, total score, and activities of daily living and motor subscores). The total score improved by six points, the activities of daily living subscore by one point, and motor subscore by five points (table 2). The minimally important differences for the UPDRS have been reported in two studies. One analysed data from two independent randomised controlled trials and concluded that the minimally important difference was eight points for the total score, between two and three points for the activities of daily living subscore, and five points for the motor score. ${ }^{66}$ The second study performed a cross sectional analysis on 653 patients with Parkinson's disease, and reported a minimally important difference of 2.3 to 2.7 points for motor subscore and 4.1 to 4.5 points for total score ${ }^{67}$ Taking into account the recommendations of both Schrag and colleagues ${ }^{66}$ and Shulman and colleagues, ${ }^{67}$ the improvements observed within this review are approaching or are at these minimally important differences. This similarity suggests that a physiotherapy intervention is beneficial in improving clinician rated motor symptoms and may have a positive effect on activities of daily living. However, we found no effect on patient rated quality of life (measured using the Parkinson's disease questionnaire 39).

Over the past decade, steps have been taken to provide best practice consensus in the form of Dutch guidelines for physical therapy in patients with Parkinson's disease (Koninklijk Nederlands Genootschap voor Fysiotherapie). ${ }^{12}$ However, this publication provides a guidance framework rather than a recipe for treatment. Additionally, Parkinson's disease is recognised as a complex condition with an individualised presentation. ${ }^{68}$ For this reason, Morris and colleagues ${ }^{69}$ recognised the importance of the physiotherapist understanding the specific experience of Parkinson's disease in each patient, and advocated that treatment be tailored to fit a person's complaints, lifestyle, and personal interests, as opposed to a "one size fits all" approach. We found no evidence of any differences in the treatment effect between the different physiotherapy interventions. However, data within each physiotherapy intervention were limited, and these comparisons were based on indirect comparisons, which should be interpreted with caution. Therefore, physiotherapy interventions should be compared against each other within rigorous trial designs to determine which, if any, are effective. This analysis could provide therapists with a menu of treatment strategies from which they can devise individualised interventions.

\section{Limitations of the review}

The methodological quality and reporting of the majority of trials was variable, and often inadequate. Of 39 trials, only 18 provided information on the randomisation method and only five used a central randomisation procedure to ensure concealment of treatment allocation. Blinded assessors were used in 24 studies, and only nine reported using intention to treat analysis. The lack of information in many reports may not necessarily indicate poor implementation within the trial, but without this information, the level of bias within each trial is difficult to assess. The need for further improvement in the methodological quality of trials in physiotherapy for Parkinson's disease was noted in another recent systematic review. ${ }^{70}$ Future trials therefore need to ensure that their designs fulfil the requirements of a methodologically sound, large randomised controlled trial, and that the reporting follows the CONSORT guidelines. $^{71}$

Furthermore, the trials included in the review were relatively small, and most compared the effect of physiotherapy intervention with no intervention over a short period of time ( $<$ three months). Three trials followed up their patients for three months or longer, but all used different follow-up periods, the longest being six months. ${ }^{33763}$ With such limited data, no meaningful meta-analysis could be performed on these longer term data to assess the duration of any improvement after therapy. It is also important to consider the results alongside the possibility of a so-called honeymoon effect ${ }^{72}$ in the period during or just after physiotherapy, which could inflate the treatment effect in favour of physiotherapy. For a long term disease such as Parkinson's disease, the effect of therapy over a much longer period is needed.

Studies included in the review all used standard physiotherapy and Parkinson's disease outcomes. However, Parkinson's disease is a multidimensional disease, and many important outcomes were either poorly or not reported. This included data for quality of life, the number of falls, depression and anxiety, adverse events, and the health of the carer supporting the person with Parkinson's disease. We saw little focus on patient orientated outcomes, without which studies cannot necessarily capture the difficulties experienced by patients in everyday life or their opinions on treatment acceptability and personal improvements. Patient reported outcomes such as the walk $12 \mathrm{G}$ scale, which has been shown to have validity in Parkinson's disease, ${ }^{73}$ should be more commonly used in trials of physiotherapy to increase the effect of the studies themselves and of subsequent meta-analyses. Furthermore, none of the reports included a health economics analysis of the physiotherapy intervention studied, and therefore, little is known about the cost effectiveness and economic value of these various therapies. Implementation of a community based professional network of physiotherapists working according to evidence based recommendations has been shown to reduce costs of provision of healthcare compared with usual care. ${ }^{74}$ Unfortunately, the evidence base, required to inform the types of techniques which should be recommended for use in these networks, is inconclusive.

Outcome reporting bias may have created a deceptively positive impression of the effectiveness of the studied interventions. Unfortunately, the proportion of outcomes that went unreported could not be assessed here, owing to a lack of information on trial protocol.

\section{Implications for research}

A larger and better quality body of evidence is required before a recommendation for change in practice can be made. The majority of the studies in this review were small and had a short follow-up period. Larger randomised controlled trials are needed, particularly those focusing on improving trial methodology and reporting. Rigorous methods of randomisation should be used and the allocation of treatment be adequately concealed. Data should be analysed according to intention to treat principles, and trials should be reported according to CONSORT guidelines. ${ }^{71}$ This review also illustrates the need for the universal use of relevant, reliable, and sensitive outcome measures. Additionally, only three trials looked at the benefit of physiotherapy intervention in the longer term. To assess 
whether or how long any improvement owing to physiotherapy intervention may last, long term follow-up should be performed without crossover from control to active intervention. Moreover, this review highlights the variety of physiotherapy interventions being used in the treatment of Parkinson's disease. More specific trials with improved treatment strategies are needed to underpin the most appropriate choice of physiotherapy intervention.

We thank all the original trialists and people who performed the trials that contributed to this meta-analysis; the patients who agreed to help improve the assessment of Parkinson's disease treatment by taking part in these trials; Parkinson's UK for their funding; the UK Department of Health, whose core support for Birmingham Clinical Trials Unit made this review possible; and Alex Furmston, Kinga Malottki, Mohammad Tokhi, and Manijeh Ghods, who provided translations for foreign papers.

This paper is based on a Cochrane review by the same authors. Cochrane reviews are regularly updated as new evidence emerges and in response to comments and criticisms. This work has been undertaken to update the physiotherapy versus placebo or no intervention in Parkinson's disease first published in 2001. The Cochrane Library should be consulted for the most recent version of the review.

Contributors: CEC, RS, CS, KW, and $\mathrm{NI}$ contributed to the design of the protocol. CLT, RS, LS, and CPH designed and implemented the searches. CLT, RS, CM, SP, and CPH selected the studies. CLT, SP, $\mathrm{CM}$, and $\mathrm{CPH}$ undertook data extraction and assessment of risk of bias. $\mathrm{CM}$, who throughout the review and analysis period was a research physiotherapist, provided expertise on technical aspects of the project as necessary. CLT, SP, NI, and CPH were involved in the data analysis. All authors were involved in interpretation of the review. NI is the study guarantor.

Funding: This review was funded by Parkinson's UK and the UK Department of Health, which provided the University of Birmingham Clinical Trials Unit with core support.

Competing interests: All authors have completed the Unified Competing Interest form at www.icmje.org/coi_disclosure.pdf (available on request from the corresponding author) and declare: support from the Department of Health for the submitted work; CEC, RS, CS, KW, and $\mathrm{NI}$ had support from Parkinson's UK; SP, CM, CEC, CS, KW, and NI are either recruiting to or involved in the running of the UK PD REHAB trial.

Ethical approval: Not required.

Data sharing: No additional data available.

1 Rubenis J. A rehabilitational approach to the management of Parkinson's disease. Parkinsonism \& Relat Dis 2007;13:S495-7.

2 Rascol O, Payoux P, Ferreira J, Brefel-Courbon C. The management of patients with early Parkinson's disease. Parkinsonism \& Relat Dis 2002;9:61-7.

3 Nijkrake MJ, Keus SH, Kalf JG, Sturkenboom IH, Munneke M, Kappalle AC, et al. Allied health care interventions and complementary therapies in Parkinson's disease [abstract]. Parkinsonism \& Relat Dis 2007;13(suppl 3):S488-94.

4 Schrag A, Jahanshahi M, Quinn N. How does Parkinson's disease affect quality of life? A comparison with quality of life in the general population. Mov Disord 2000;15:1112-8.

5 Van Nimwegen M, Speelman AD, Hofman-van Rossum EJ, Overeem S, Deeg DJ, Borm GF, et al. Physical inactivity in Parkinson's disease. J Neurol 2011;258:2214-21.

6 Gage H, Storey L. Rehabilitation for Parkinson's disease: a systematic review of available evidence. Clin Rehab 2004;18:463-82.

7 Robertson D. Developing and delivering services. In: Playford D, ed. Neurological rehabilitation of Parkinson's disease. Martin Dunitz, 2003.

8 Post B, van der Eijk M, Munneke M, Bloem BR. Multidisciplinary care for Parkinson's disease: not if, but how! Postgrad Med J 2011;87:575-8.

9 Robertson D, Aragon A, Moore G, Whelan L. Rehabilitation and the interdisciplinary team. In: Playfer J, ed. Parkinson's disease in the older patient. Radcliffe Publishing, 2008.

10 Plant R, Jones D, Walton G, Ashburn A, Lovegreen B, Handford F, et al. Physiotherapy for people with Parkinson's disease: UK best practice short report. Institution of Rehabilitation, University of Northumbria, 2000.

11 Deane K, Jones DE, Playford ED, Ben-Shlomo Y, Clarke CE. Physiotherapy versus placebo or no intervention in Parkinson's disease. Cochrane Database Syst Rev 2001;3:CD002817.

12 Keus S, Hendriks HJ, Bloem BR, Bredero-Cohen AB, De Goede CJ, Van Haaran M, et al. Clinical practice guidelines for physical therapy in patients with Parkinson's disease [abstract]. Dutch J Physiother 2004;114(suppl 3):S1-94.

13 Mutch WJ, Strudwick A, Roy SK, Downie AW. Parkinson's disease-disability, review, and management. BMJ 1986;293:675-7.
14 Yarrow S. Members' 1998 survey of the Parkinson's Disease Society of the United Kingdom. In: Percival R, Hobson, eds. Parkinson's disease: Studies in psychological and social care. BPS Book, 1999: 79-92.

15 Keus SH, Munneke M, Nijkrake MJ, Kwakkel G, Bloem BR. Physical therapy in Parkinson's disease: evolution and future challenges. Mov Disord 2009;24:1-14

16 National Collaborating Centre for Chronic Parkinson's Disease. National clinical guideline for diagnosis and management in primary and secondary care. Royal College of Physicians, 2006.

17 Keus SH, Bloem BR, Hendriks EJ, Bredero-Cohen AB, Munneke M; Practice Recommendations Development Group. Evidence-based analysis of physical therapy in Parkinson's disease with recommendations for practice and research. Mov Disord 2007;22:451-60.

18 Parkinson's Disease Society. Life with Parkinson's today—room for improvement. Parkinson's Disease Society, 2008.

19 Goodwin VA, Richards SH, Taylor RS, Taylor AH, Campbell JL. The effectiveness of exercise interventions for people with Parkinson's disease: a systematic review and meta-analysis. Mov Disord 2008;23:631-40.

20 Mehrholz J, Friis R, Kugler J, Twork S, Storch A, Pohl M. Treadmill training for patients with Parkinson's disease. Cochrane Database Syst Rev 2010;1:CD007830.

21 Tomlinson CL, Patel S, Meek C, Clarke CE, Stowe R, Shah L, et al. Physiotherapy versus placebo or no intervention in Parkinson's disease. Cochrane Database Syst Rev 2012;7:CD002817.

22 Higgins JPT, Green S, eds. Cochrane handbook for systematic reviews of interventions. Version 5.1.0. Cochrane Collaboration, 2011.

23 Fleiss JL. The statistical basis of meta-analysis. Stat Methods Med Res 1993;2:121-45.

24 Deeks JJ, Altman DG, Bradburn MJ. Statistical methods for examining heterogeneity and combining results from several studies in meta-analysis. In: Egger M, ed. Systematic reviews in health care: meta-analysis in context. BMJ Publication Group, 2001

25 Chandler C, Plant R. A targeted physiotherapy service for people with Parkinson's disease from diagnosis to end stage: a pilot study. In: Percival R, Hobson P, eds. Parkinson's disease: studies in psychological and social care. BPS Books, 1999:256-69.

26 Ellis T, De Goede CJ, Feldman RG, Wolters EC, Kwakkel G. Efficacy of a physical therapy program in patients with Parkinson's disease: a randomized controlled trial. Arch Phys Med Rehab 2005;86:626-32.

27 Fisher BE, Wu AD, Salem GJ, Song J, Lin CH, Yip J, et al. The effect of exercise training in improving motor performance and corticomotor excitability in people with early Parkinson's disease. Arch Phys Med 2008;89:1221-9.

28 Homann CN, Crevenna R, Kojnig H, Kurzl B, Reinprecht S, Wenzel K, et al. Can physiotherapy improve axial symptoms in parkinsonian patients? A pilot study with computerized movement analysis battery Zebris [abstract]. Mov Disord 1998;13(suppl 2):S234

29 Keus SHJ, Bloem BR, Van Hilten JJ, Ashburn A, Munneke M. Effectiveness of physiotherapy in Parkinson's disease: the feasibility of a randomised controlled trial. Parkinsonism Relat Disord 2007;13:115-21.

30 Stack E, Roberts H, Ashburn A. The PIT: SToPP trial-a feasibility randomised controlled trial of home-based physiotherapy for people with Parkinson's disease using video-based measures to preserve assessor blinding. Parkinsons Dis 2012;360:231.

31 Talakad S, Ganesan M, Gupta A, Pal PK, Trichur R. Effect of partial weight supported treadmill gait training on cardiovascular dynamics in patients with Parkinson's disease. Mov Disord 2011;26(suppl 2):S173.

32 Allen NE, Canning CG, Sherrington C, Lord SR, Latt MD, Close JCT, et al. The effects of an exercise program on fall risk factors in people with Parkinson's disease: a randomized controlled trial [abstract]. Mov Disord 2010;259(suppl 2):S1217-25.

33 Ashburn A, Fazakarley L, Ballinger C, Pickering R, McLellan LD, Fitton C. A randomised controlled trial of a home based exercise programme to reduce the risk of falling among people with Parkinson's disease. J Neurol Neurosurg Psychiatry 2007;78:678-84.

34 Boehm RL, Almeida QJ, Knobl P. Sensory attention focused exercise in Parkinson's disease: a randomized double-crossover trial [abstract]. Mov Disord 2011;26(suppl 2):S331-2.

35 Cerri C, Arosio A, Biella AM, Premoselli S, Piccini L. Physical exercise therapy in Parkinson's [abstract]. Mov Disord 1994;9(suppl 1):68.

36 Goodwin VA, Richards SH, Henley W, Ewings P, Taylor AH, Campbell JL. An exercise intervention to prevent falls in people with Parkinson's disease: a pragmatic randomised controlled trial. J Neurol Neurosurg Psychiatry 2012;82:1232-8.

37 Klassen L, Dal Bello-Haas V, Sheppard M, Metcalfe A. Evaluating the benefits of group exercise and group exercise and education programs for individuals with Parksinson's disease (PD) [abstract]. Physiotherapy 2007;93(suppl 1):S91.

38 Mak MK, Hui-Chan CW. Cued task-specific training is better than exercise in improving sit-to-stand in patients with Parkinson's disease: a randomized controlled trial. Mov Disord 2008;23:501-9.

39 Meek C, Sackley CM, Clarke CE, Soundy AA, Winward C, Esser P, et al. Long-term individual fitness enablement (LIFE) for Parkinson's disease: a feasibility study [abstract]. Mov Disord 2010;25(suppl 3):S713

40 Sage MD, Almeida QJ. Symptom and gait changes after sensory attention focused exercise vs aerobic training in Parkinson's disease. Mov Disord 2009;24:1132-8.

41 Schenkman M, Cutson TM, Kuchibhatla M, Chandler J. Pieper CF, Ray L, et al. Exercise to improve spinal flexibility and function for people with Parkinson's disease: a randomized, controlled trial. J Am Geriatr Soc 1998;46:1207-16.

42 Schilling BK, Ledoux MS, Pfeiffer RF, Karlage RE, Weise LW, Flavo MJ. Effects of lower-body resistance training in persons with Parkinson's disease [abstract]. Mov Disord 2008:23(suppl 1):S639.

43 Stozek J, Rudzinska M, Longawa K, Szczudik A. The effect of the complex rehabilitation on posture and gait in Parkinson disease [abstract]. Neurol Neurochir Pol 2003;37(suppl 5):S67-81.

44 Taheri H, Pejhan A, Taherzadeh J, Seyedahmadi M, Keavanloo F. Effect of a physical therapy program based on balance and gait in patients with Parkinson. $J$ Isfahan Med Sch 2011:29:1183-91.

45 Thaut MH, McIntosh GC, Rice RR, Miller RA, Rathbun J, et al. Rhythmic auditory stimulation in gait training for Parkinson's disease patients. Mov Disord 1996;11:193-200.

46 Cakit BD, Saracoglu M, Genc H, Erdem HR, Inan L. The effects of incremental speed-dependent treadmill training on postural instability and fear of failing in Parkinson's disease. Clin Rehab 2007;21:698-705.

47 Canning CG, Allen NE, Dean CM, Goh L, Fung VSC. Home-based treadmill training for individuals with Parkinson's disease: a randomized controlled pilot trial. Clin Rehabil 2012: published online 18 January. 


\section{What is already known this on this topic}

Referral rates for physiotherapy in Parkinson's disease are historically low in the UK

Evidence from published trials and guidelines have suggested potential benefits of physiotherapy for patients with Parkinson's disease

\section{What this study adds}

A variety of physiotherapy methods currently exist for treating Parkinson's disease

Physiotherapy could provide clinically meaningful benefits in the short term for patients, although many relevant trials have been of low methodological quality, small size, and short duration. Indirect comparisons indicate little difference in treatment effect between interventions

It is uncertain whether physiotherapy is beneficial in the longer term, and if so, which type of physiotherapy is best to deliver

48 Ganesan M, Pal PK, Gupta A, Talakad S. Effect of partial weight supported treadmill gait training on balance in patients of Parkinson's disease [abstract]. Parkinsonism Relat Disord 2010;16(suppl 1):S66.

49 Kurtais $\mathrm{Y}$, Kutlay S, Tur BS, Gok H, Akbostanci C. Does treadmill training improve lower-extremity tasks in Parkinson disease? A randomized controlled trial. Clin J Sport Med 2008;18:289-91.

50 Protas EJ, Mitchell K, Williams A, Qureshy H, Caroline K, Lai EC. Gait and step training to reduce falls in Parkinson's disease. Neurorehabilitation 2005;20:183-90.

51 Shankar A, Labelle N, Derwent L, Bonfield S, Eliasziw M, Hu B, et al. Treadmill-walking with music shows a synergistic improvement in gait and balance in patients with Parkinson's disease: a randomized controlled trial [abstract]. Mov Disord 2009;24(suppl 1):S281-2.

52 Almeida QJ, Bhatt H. A manipulation of visual feedback during gait training in Parkinson's disease. Parkinsons Dis 2012;2012:508720.

53 De Bruin N, Bonfield S, Hu B, Suchowersky O, Doan J, Brown L. Walking while listening to music improves gait performance in Parkinson's disease [abstract]. Mov Disord 2008;23(suppl 1):S667.

54 De Bruin N, Doan J, Turnbull G, Bonfield S, Sucherwosky O, Hu B, et al. The effects of a music accompanied walking program on obstacle crossing behaviours in people with Parkinson's disease [abstract]. Mov Disord 2010;25(suppl 3):S697.

55 Haase $M$. The immediate effects of rhythmic arm swing and finger tapping exercises on gait of Parkinson's patients [PhD thesis abstract]. ProQuest, 2011.

56 Lehman DA, Toole T, Lofald D, Hirsch MA. Training with verbal instructional cues results in near-term improvement of gait in people with Parkinson's disease. J Neurol Phys The 2005;29:2-8.

57 Nieuwboer A, Kwakkel G, Rochester L, Jones D, Van Wegen E, Willems AM, et al. Cueing training in the home improves gait-related mobility in Parkinson's disease: the RESCUE trial. J Neurol Neurosurg Psychiatry 2007;78:134-40.

58 Shankar A, de Bruin N, Bonfield S, Derwent L, Eliasziw M, Hu B, et al. Benefit of music therapy in patients with Parkinson's disease: a randomized controlled trial [abstract]. Mov Disord 2008;23(suppl 1):S608.

59 Duncan RP, Earhart GM. Randomized controlled trial of community-based dancing to modify disease progression in Parkinson disease. Neurorehabil Neural Repair 2012;26:132-43.

60 Hackney ME, Earhart GM. Health-related quality of life and alternative forms of exercise in Parkinson disease. Parkinsonism Relat Disord 2009;15:644-8.

61 Marjama-Lyons J, Smith L, Mylar B, Nelson J, Holliday G, Seracino D. Tai chi and reduced rate of falling in Parkinson's disease: a single-blinded pilot study [abstract]. Mov Disord 2002;17(suppl 5):S190.

62 Purchas MA, MacMahon DG. The effects of tai chi training on general wellbeing and motor performance in patients with Parkinson's disease (PD): a pilot study [abstract]. Mov Disord 2007;22(suppl 16):S260.
63 Schmitz-Hubsch T, Pyfer D, Kielwein K, Fimmers R, Klockgether T, Wullner U. Qigong exercise for the symptoms of Parkinson's disease: a randomized, controlled pilot study. Mov Disord 2006;21:543-8

64 Perry J, Garrett M, Gronley JK, Mulroy SJ. Classification of walking handicap in the stroke population. Stroke 1995;26:982-9.

65 Steffen T, Seney M. Test-retest reliability and minimal detectable change on balance and ambulation tests, the 36-Item Short-Form Health Survey, and the unified Parkinson disease rating scale in people with parkinsonism. Phys Ther 2008;88:733-46.

66 Schrag A, Sampaio C, Counsell N, Poewe W. Minimal clinically important change on the Unified Parkinson's Disease Rating Scale. Mov Disord 2006;21:1200-7.

67 Shulman LM, Gruber-Baldini AL, Anderson KE, Fishman PS, Reich SG, Weiner WJ. The clinically important difference on the Unified Parkinson's Disease Rating Scale. Arch Neurol 2010;67:64-70.

68 Van der Marck MA, Kalf JG, Sturkenboom IH, Nijkrake MJ, Munneke M, Bloem BR. Multidisciplinary care for patients with Parkinson's disease [abstract]. Parkinsonism \& Relat Disord 2009;15(suppl 3):S219-23.

69 Morris ME, Martin CL, Schenkman ML. Striding out with Parkinson disease: evidence-based physical therapy for gait disorders. Phys Ther 2010;90:280-8.

70 Kwakkel G. De Goede CJT, Van Wegen EEH. Impact of physical therapy for Parkinson's disease: a critical review of the literature [abstract]. Parkinsonism \& Relat Disord 2007;13(suppl):S478-87.

71 Schulz KF, Altman DG, Moher D. CONSORT 2010 statement: updated guidelines for reporting parallel group randomised trials. BMJ 2010;340:c332.

72 Goetz CG, Wuu J, McDermott MP, Alder CH, Fahn S, Freed CR, et al. Placebo response in Parkinson's disease: comparisons among 11 trials covering medical and surgical interventions. Mov Disord 2008;23:690-9.

73 Bladh S, Nilsson MH, Hariz GM, Westergren A, Hobart J, Hagell P. Psychometric performance of a generic walking scale (Walk-12G) in multiple sclerosis and Parkinson's disease. J Neurol 2012;259:729-38.

74 Munneke M, Nijkrake M, Keus SHJ, Kwakkel G, Berendse HW, Roos RAC, et al. Efficacy of community-based physiotherapy networks for patients with Parkinson's disease: a cluster-randomised trial. Lancet Neurol 2010:9:46-54.

Accepted: 04 July 2012

\section{Cite this as: BMJ 2012;345:e5004}

This is an open-access article distributed under the terms of the Creative Commons Attribution Non-commercial License, which permits use, distribution, and reproduction in any medium, provided the original work is properly cited, the use is non commercial and is otherwise in compliance with the license. See: http://creativecommons.org/licenses/bync/2.0/ and http://creativecommons.org/licenses/by-nc/2.0/legalcode. 


\section{Tables}

Table 1/ Physiotherapy intervention classifications and trial characteristics

\begin{tabular}{|c|c|c|c|c|c|c|c|c|}
\hline $\begin{array}{l}\text { Physiotherapy } \\
\text { intervention }\end{array}$ & Number of trials & $\begin{array}{c}\text { Total number } \\
\text { of } \\
\text { participants } \\
\text { (\% male })\end{array}$ & $\begin{array}{c}\text { Mean age } \\
\text { (years) }\end{array}$ & $\begin{array}{l}\text { Mean stage } \\
\text { on Hoehn } \\
\text { and Yahr } \\
\text { scale }\end{array}$ & $\begin{array}{l}\text { Mean } \\
\text { duration of } \\
\text { Parkinson's } \\
\text { disease } \\
\text { (years) }\end{array}$ & $\begin{array}{l}\text { Duration of } \\
\text { treatment } \\
\text { sessions } \\
\text { (min) }\end{array}$ & $\begin{array}{l}\text { Duration of } \\
\text { trial period }\end{array}$ & $\begin{array}{c}\text { Examples of types of } \\
\text { therapy }\end{array}$ \\
\hline Physiotherapy & $7^{25,26,27,28,29,30,31}$ & $244(69)$ & 65 & 2.4 & 4 & $30-60$ & 4-12 months & $\begin{array}{l}\text { Bobath training; gait and } \\
\text { balance exercises; hands-on } \\
\text { techniques; education and } \\
\text { advice on transfer, posture, } \\
\text { physical fitness }\end{array}$ \\
\hline Exercise & $14^{32,33,34,35,36,37,38,39,40,41,42,43,44,45}$ & $769(60)$ & 69 & 2.6 & 6 & $30-120$ & 3-24 weeks & $\begin{array}{l}\text { Strengthening and balance } \\
\text { training; walking; falls } \\
\text { prevention; neuromuscular } \\
\text { facilitation; resistance } \\
\text { exercise; aerobic training; } \\
\text { education; relaxing techniques }\end{array}$ \\
\hline Treadmill & $8^{27,31,46,47,48,49,50,51}$ & $179(61)$ & 68 & 2.4 & 5 & $30-60$ & 4-8 weeks & $\begin{array}{l}\text { Walking on treadmill with } \\
\text { speed or incline adjustments; } \\
\text { body weight supported } \\
\text { treadmill training; step and gait } \\
\text { training }\end{array}$ \\
\hline Cueing & $9^{38,45,52,53,54,55,56,57,58}$ & $371(59)$ & 67 & 2.6 & 7 & $4-30$ & $\begin{array}{l}\text { Single session } \\
\text { of } 13 \text { weeks }\end{array}$ & $\begin{array}{l}\text { Three types of cueing: audio } \\
\text { (music, spoken instructions); } \\
\text { visual (computer images); } \\
\text { sensory (vibration) }\end{array}$ \\
\hline Dance & $2^{59,60}$ & $120(63)$ & 69 & 2.3 & 7 & 60 & $12-13$ weeks & Tango; waltz; foxtrot \\
\hline Martial arts & $4^{60,61,62,63}$ & $143(74)$ & 65 & 2.1 & 6 & 60 & 12-24 weeks & Tai chi; qigong \\
\hline
\end{tabular}

For one trial, ${ }^{31} 60$ patients split between physiotherapy and treadmill categories not included in table because group split not given. For multiple arm trials, which are included in more than one intervention type, control arm patients $(n=59)$ were counted twice. Web table 1 provides detailed information on individual trials. 


\begin{tabular}{|c|c|c|c|c|c|c|}
\hline \multicolumn{7}{|c|}{ Table 2| Summary of results } \\
\hline Outcomes & $\begin{array}{l}\text { No of trials; no of } \\
\text { comparisons }\end{array}$ & Physiotherapy interventions & $\begin{array}{c}\text { No of } \\
\text { participants }\end{array}$ & Mean difference $(95 \% \mathrm{Cl})$ & Heterogeneity & Subgroup \\
\hline \multicolumn{7}{|l|}{ Gait } \\
\hline Speed $(\mathrm{m} / \mathrm{s})$ & $\begin{array}{c}15 ; \\
19^{25,26,27,32,34,38,40,45,47,50,52,53,55,57,60} \\
\end{array}$ & $\begin{array}{l}\text { General physiotherapy, exercise, } \\
\text { treadmill, cueing, dance, martial } \\
\text { arts }\end{array}$ & 814 & 0.04 (0.02 to 0.06 ), $P<0.001$ & $P=0.55$ & $P=0.25$ \\
\hline 2 or 6 min walk test $(\mathrm{m})$ & $6 ; 7^{39,41,42,4,7,59,60}$ & $\begin{array}{l}\text { Exercise, treadmill, dance, martial } \\
\text { arts }\end{array}$ & 242 & 13.37 (0.55 to 26.20$), P=0.04$ & $P=0.44$ & $P=0.19$ \\
\hline 10 or $20 \mathrm{~m}$ walk test $(\mathrm{s})$ & $4 ; 4^{39,41,43,49}$ & Exercise, treadmill & 169 & 0.40 (0.00 to 0.80$), P=0.05$ & $P=0.19$ & $P=0.51$ \\
\hline $\begin{array}{l}\text { Freezing of gait } \\
\text { questionnaire }\end{array}$ & $4 ; 4^{32,57,59,60}$ & Exercise, cueing, dance & 298 & $\begin{array}{c}-1.41(-2.63 \text { to }-0.19) \\
P=0.02\end{array}$ & $P=0.74$ & $P=0.55$ \\
\hline Cadence (steps/min) & $7 ; 9^{27,40,45,50,53,55,57}$ & $\begin{array}{l}\text { General physiotherapy, exercise, } \\
\text { treadmill, cueing }\end{array}$ & 350 & $-1.57(-3.81$ to 0.67$), P=0.17$ & $P=0.73$ & $P=0.97$ \\
\hline Stride length $(\mathrm{m})$ & $6 ; 9^{27,45,50,53,55,60}$ & $\begin{array}{l}\text { General physiotherapy, exercise, } \\
\text { treadmill, cueing, dance, martial } \\
\text { arts }\end{array}$ & 225 & 0.03 (-0.02 to 0.08$), P=0.24$ & $P=0.33$ & $P=0.23$ \\
\hline Step length $(m)$ & $5 ; 6^{27,34,40,52,57}$ & $\begin{array}{l}\text { General physiotherapy, exercise, } \\
\text { treadmill, cueing }\end{array}$ & 383 & 0.02 (0.00 to 0.04$), P=0.06$ & $\mathrm{P}=0.71$ & $P=0.47$ \\
\hline \multicolumn{7}{|c|}{ Functional mobility and balance } \\
\hline $\begin{array}{l}\text { Timed up and go test } \\
\text { (s) }\end{array}$ & $9 ; 10^{34,36,3,7,40,42,43,5,5,5,7,60}$ & $\begin{array}{l}\text { Exercise, cueing, dance, martial } \\
\text { arts }\end{array}$ & 639 & $\begin{array}{c}-0.63(-1.05 \text { to }-0.21) \\
P=0.003\end{array}$ & $P=0.12$ & $P=0.33$ \\
\hline $\begin{array}{l}\text { Functional reach test } \\
(\mathrm{cm})\end{array}$ & $4 ; 4^{33,41,43,57}$ & Exercise, cueing & 393 & 2.16 (0.89 to 3.43$), P<0.001$ & $P=0.15$ & $P=0.48$ \\
\hline Berg balance scale & $5 ; 6^{33,36,44,46,60}$ & $\begin{array}{l}\text { Exercise, treadmill, dance, martial } \\
\text { arts }\end{array}$ & 385 & 3.71 (2.30 to 5.11 ), $P<0.001$ & $P=0.06$ & $P=0.47$ \\
\hline $\begin{array}{l}\text { Activity specific balance } \\
\text { confidence }\end{array}$ & $3 ; 3^{37,42,58}$ & Exercise, cueing & 66 & $2.40(-2.78$ to 7.57$), P=0.36$ & $P=0.61$ & $P=0.32$ \\
\hline \multicolumn{7}{|l|}{ Falls } \\
\hline Falls efficacy scale & $4 ; 4^{32,36,46,57}$ & Exercise, cueing & 353 & $-1.91(-4.76$ to 0.94$), P=0.19$ & $P=0.44$ & $P=0.28$ \\
\hline \multicolumn{7}{|c|}{ Clinician rated disability (UPDRS) } \\
\hline Total & $3 ; 4^{26,27,34}$ & $\begin{array}{l}\text { General physiotherapy, exercise, } \\
\text { treadmill }\end{array}$ & 207 & $\begin{array}{c}-6.15(-8.57 \text { to }-3.73) \\
P<0.001\end{array}$ & $P=0.03$ & $P=0.01$ \\
\hline \multicolumn{7}{|l|}{ Subscores } \\
\hline Mental & $2 ; 3^{26,27}$ & General physiotherapy, treadmill & 105 & $-0.44(-0.98$ to 0.09$), P=0.10$ & $\mathrm{P}=0.80$ & $\mathrm{P}=0.82$ \\
\hline Activities of daily living & $3 ; 4^{26,27,59}$ & $\begin{array}{l}\text { General physiotherapy, treadmill, } \\
\text { dance }\end{array}$ & 157 & $\begin{array}{c}-1.36(-2.41 \text { to }-0.30) \\
P=0.01\end{array}$ & $P=0.28$ & $\mathrm{P}=0.19$ \\
\hline Motor & $12 ; 14^{25,26,27,34,40,47,5,52,53,58,59,60,63}$ & $\begin{array}{l}\text { General physiotherapy, exercise, } \\
\text { treadmill, cueing, dance, martial } \\
\text { arts }\end{array}$ & 593 & $\begin{array}{c}-5.01(-6.30 \text { to }-3.72) \\
P<0.001\end{array}$ & $P<0.001$ & $P<0.001$ \\
\hline \multicolumn{7}{|c|}{ Patient rated quality of life (Parkinson's disease questionnaire 39) } \\
\hline Summary index & $7 ; 8^{25,32,37,39,47,57,60}$ & $\begin{array}{l}\text { General physiotherapy, exercise, } \\
\text { treadmill, cueing, dance, martial } \\
\text { arts }\end{array}$ & 405 & $-0.38(-2.58$ to 1.81$), P=0.73$ & $\mathrm{P}=0.89$ & $P=0.87$ \\
\hline Mobility subscore & $2 ; 3^{29,60}$ & $\begin{array}{l}\text { General physiotherapy, dance, } \\
\text { martial arts }\end{array}$ & 105 & $-1.43(-8.03$ to 5.18$), P=0.67$ & $P=0.11$ & $P=0.11$ \\
\hline
\end{tabular}

All results (except for the 10 or $20 \mathrm{~m}$ walk test) favoured physiotherapy intervention. 


\section{Figures}

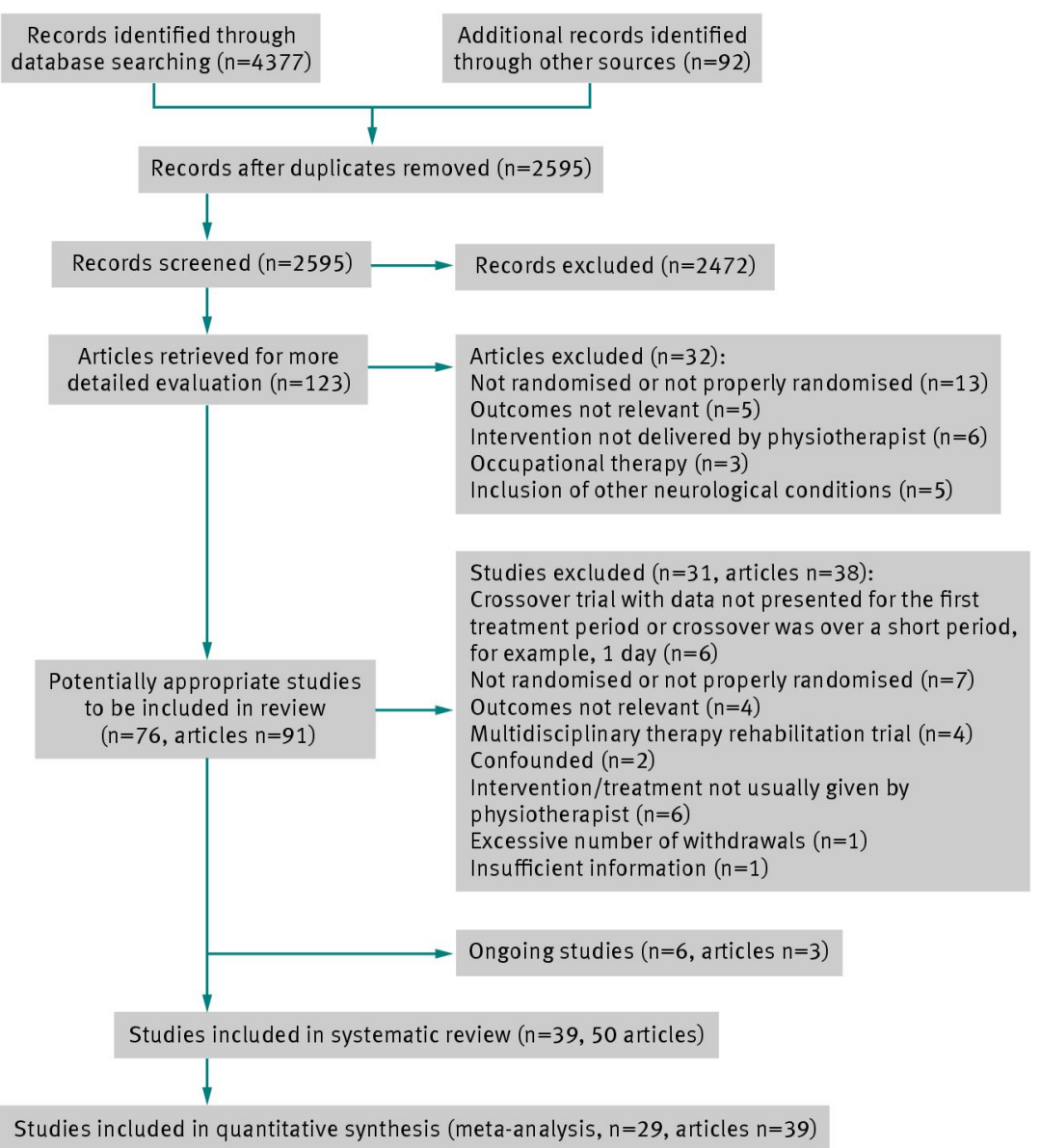

Fig 1 Trial flow diagram to summarise the stages of systematic review

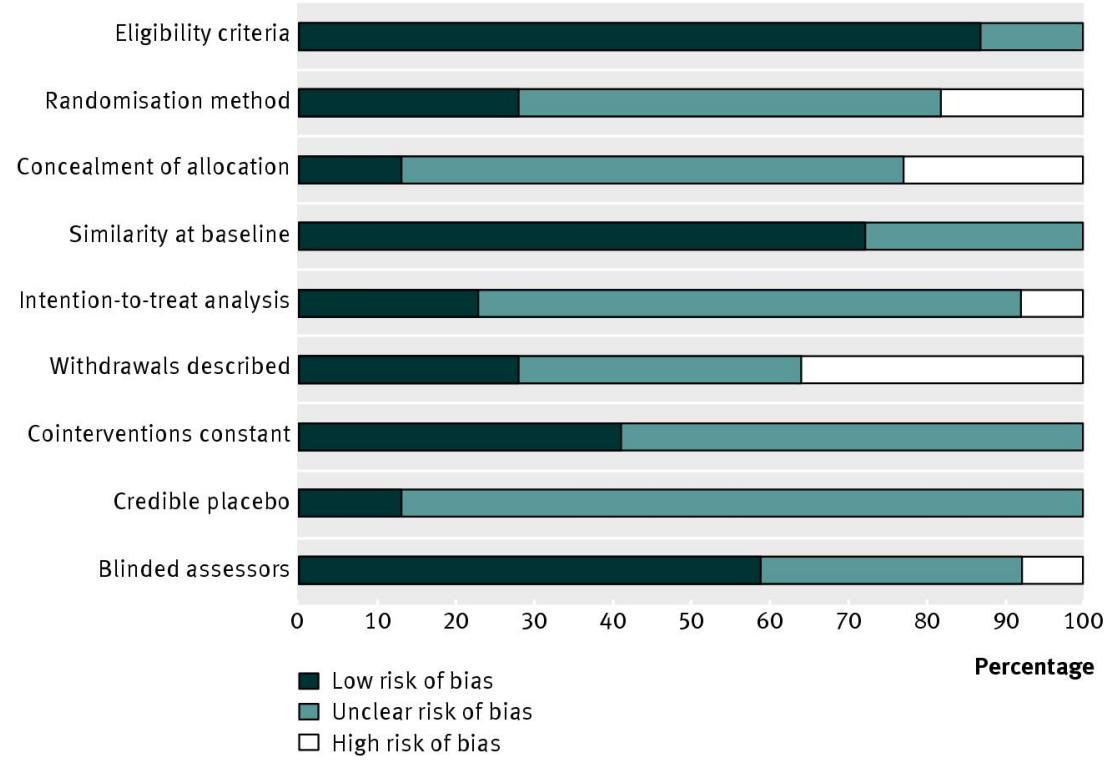

Fig 2 Review authors' judgments about each risk of bias item, presented as percentage across all included studies 


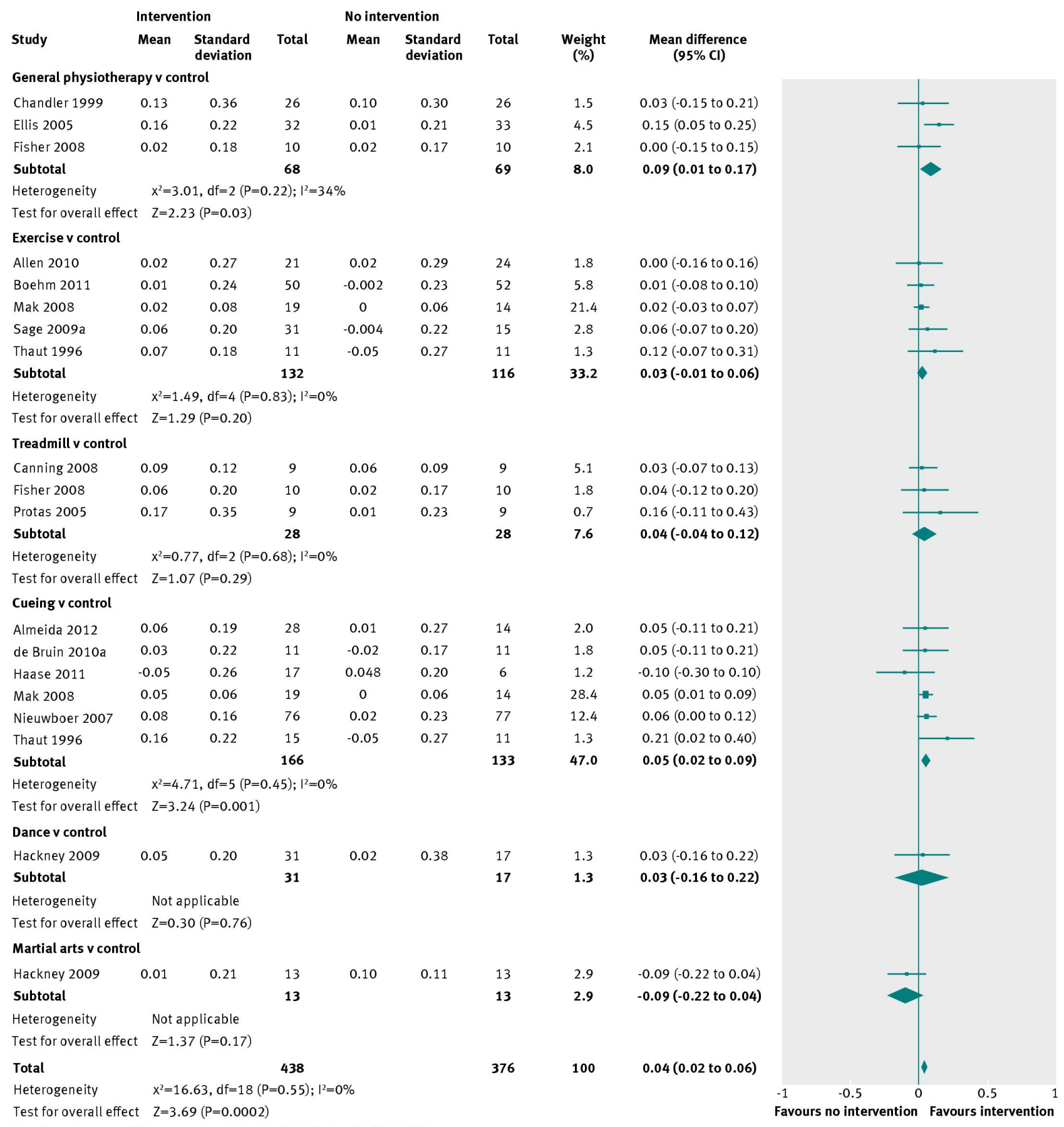

Fig 3 Comparison of physiotherapy interventions in relation to speed $(\mathrm{m} / \mathrm{s})$. Studies denoted as a or b distinguishes those published by the same first author and in the same year 


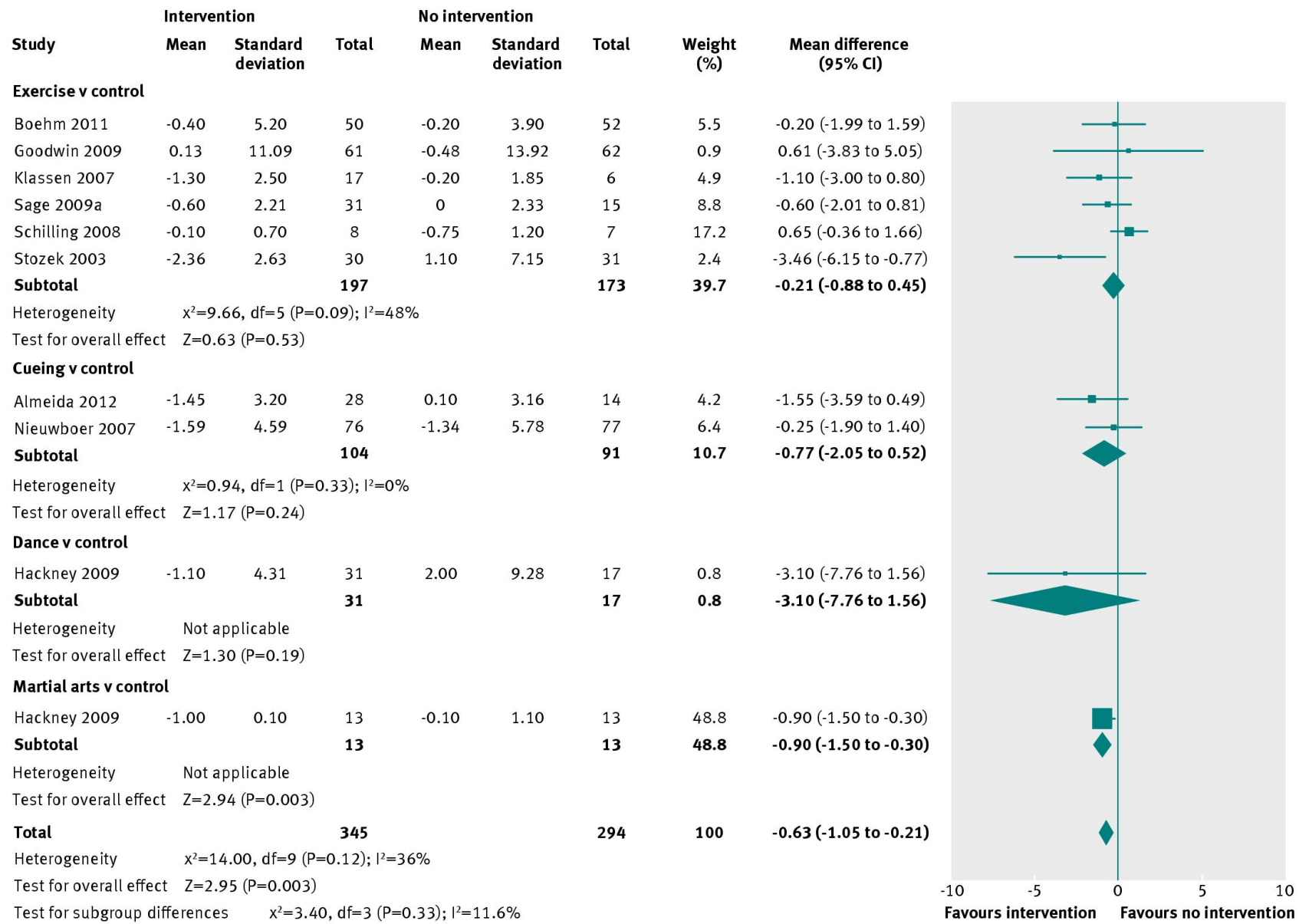

Fig 4 Comparison of physiotherapy interventions with controls in relation to the timed up and go test (s). Studies denoted as $a$ or $b$ distinguishes those published by the same first author and in the same year

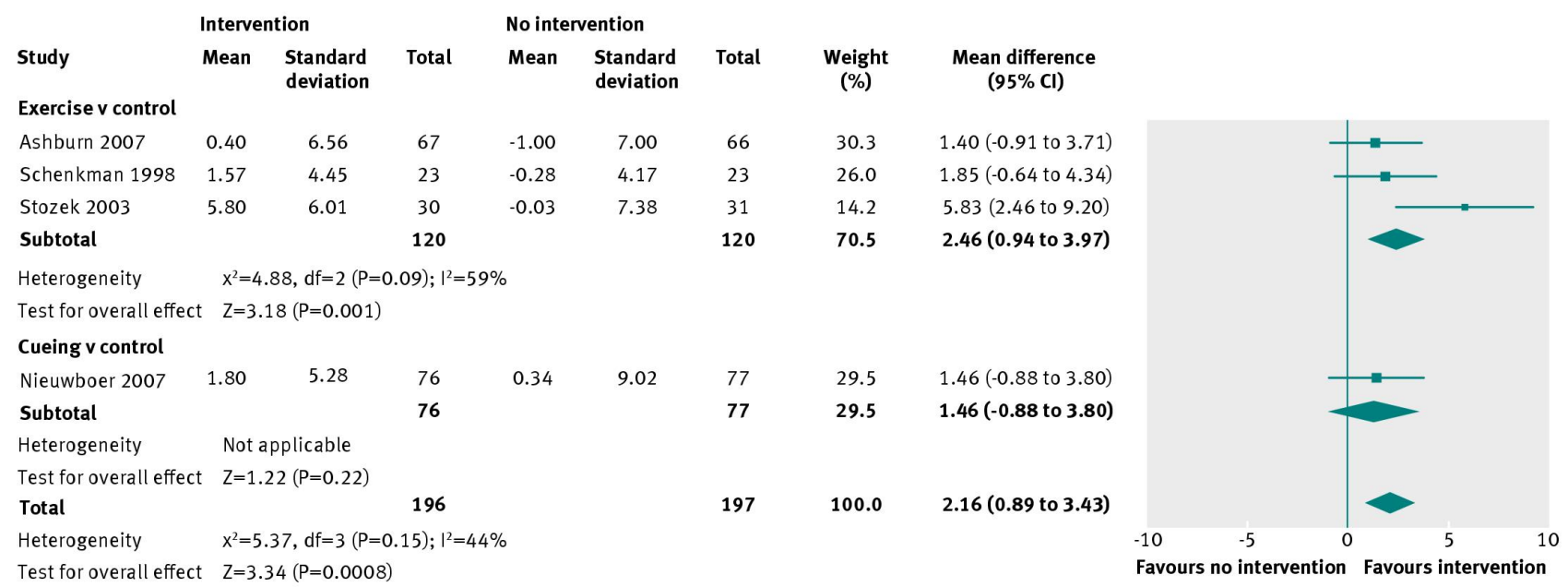

Fig 5 Comparison of physiotherapy interventions with controls in relation to the functional teach test $(\mathrm{cm})$ 


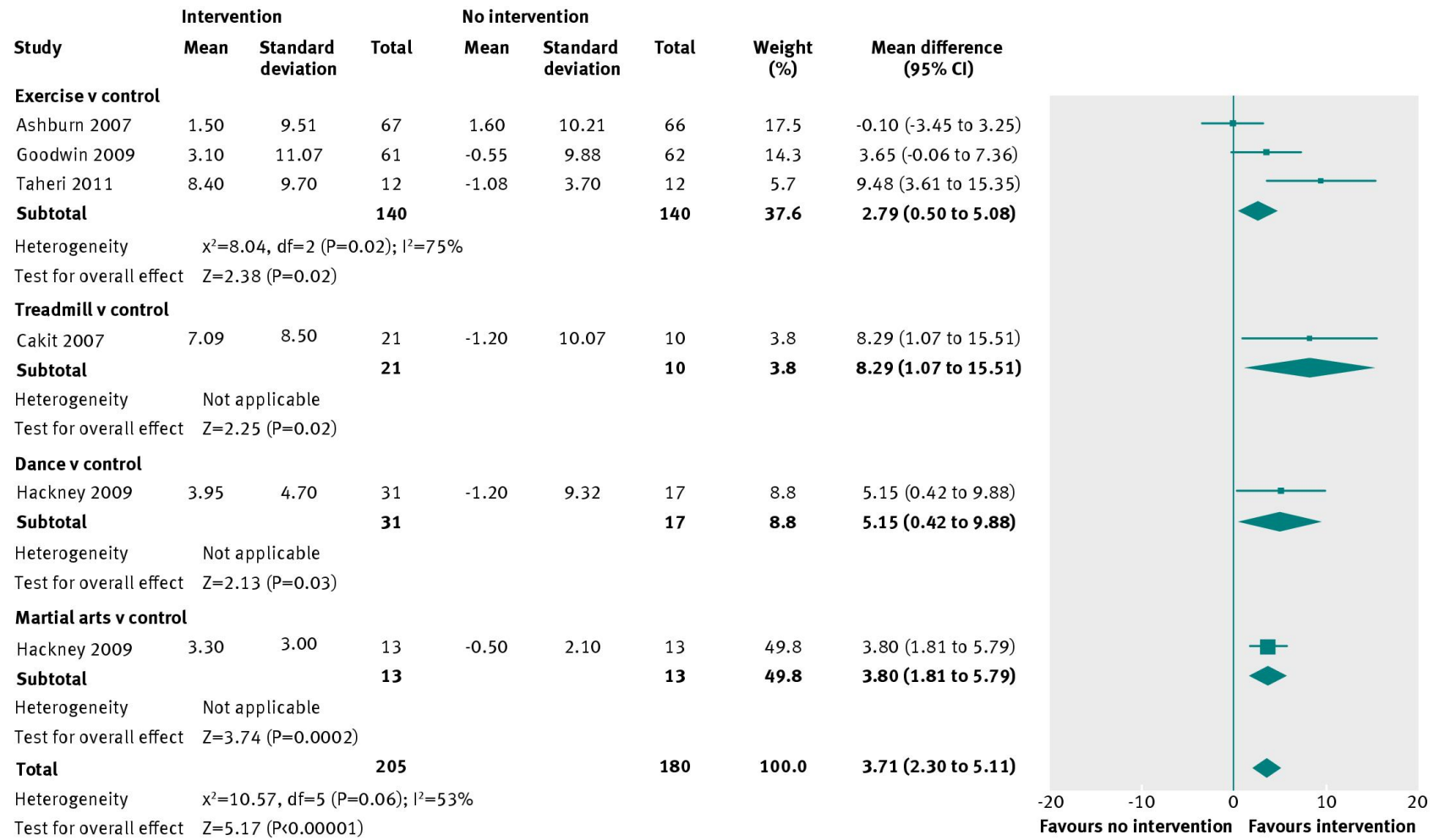

Fig 6 Comparison of physiotherapy interventions with controls in relation to the Berg balance scale. Studies denoted as a or $b$ distinguishes those published by the same first author and in the same year 


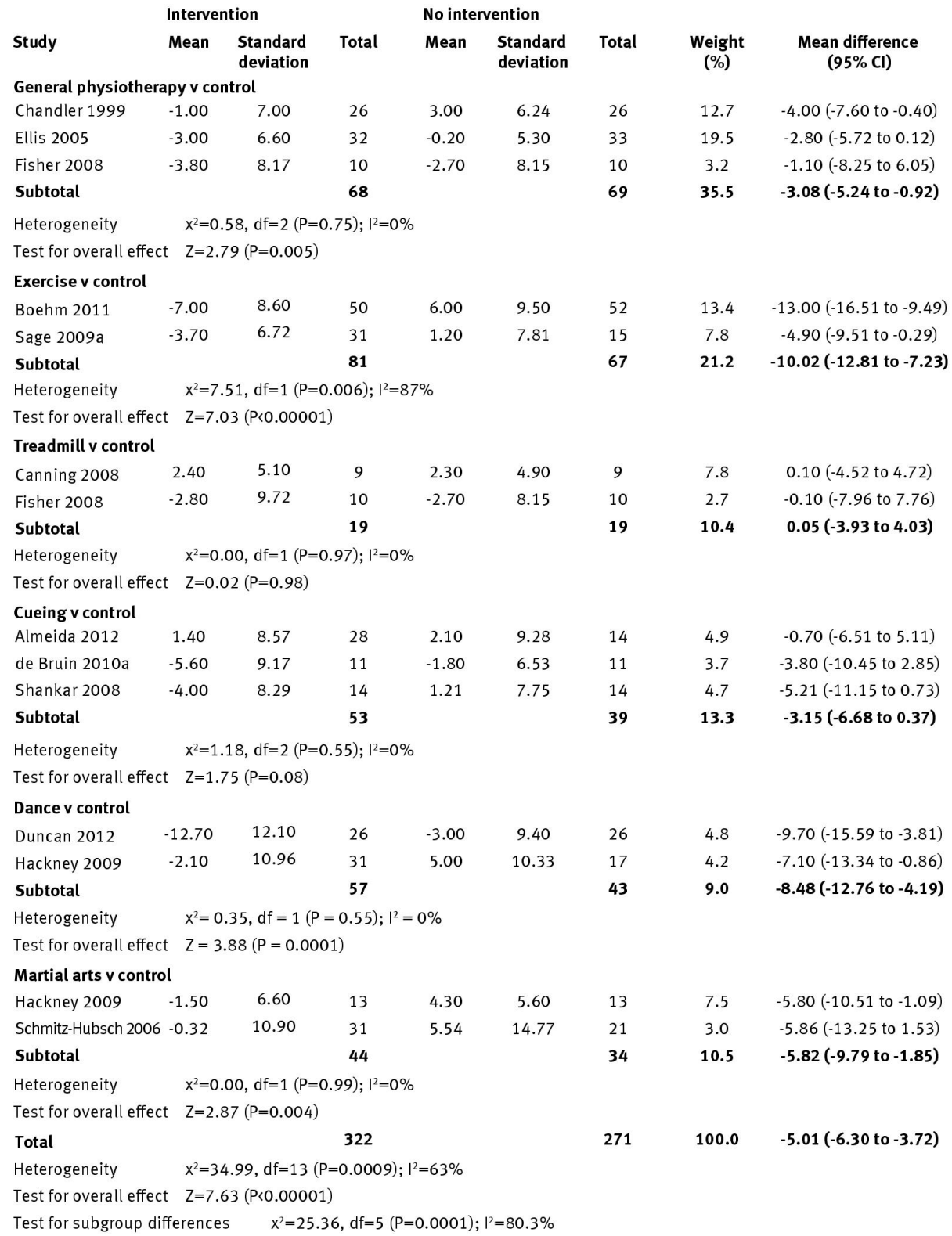

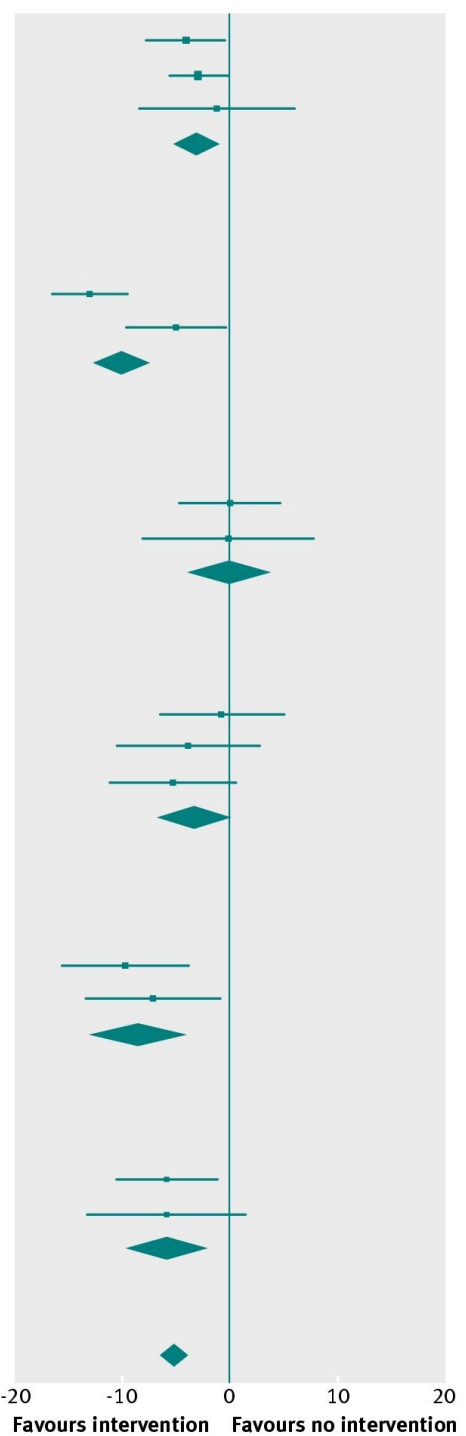

Fig 7 Comparison of physiotherapy interventions with controls in relation to the UPDRS motor subscale. Studies denoted as a or b distinguishes those published by the same first author and in the same year 